\title{
Living with loss
}

\author{
STUART LIEBERMAN \\ M.D., L.M.C.C., M.R.C.Psych. \\ Atkinson Morley's Hospital, London SW20
}

\section{Introduction}

This paper is intended to help reduce the mystery surrounding the pains and suffering we feel when we experience a loss. Although separation and loss are universal experiences, our reactions to these traumatic life events have long remained puzzling and mysterious as well as frightening. The modern attitude to grief has been to shroud it further in a conspiracy of silence in which we are unable to share openly our feelings with friends or family.

The death of a loved one is one of the most stressful events in our lives. During our subsequent reactions we can experience sensations, dream dreams, feel emotions and believe in ways which may lead us to question our morals, faith or sanity. Left alone with this distress we feel isolated, our selfesteem threatened and without support. Research has shown that the stress of severe reactions to loss can increase the likelihood of many forms of physical and mental illness. Scientific evidence has even shown that we can die from a 'broken heart' (Parkes, 1972). Stress is increased by the fear of the unknown. Stress is also made worse if the need to stifle natural grief responses is imposed on us by our friends, family and society.

More recently, research workers have brought to light many important insights into the origins, cause, meaning and importance of separation and loss as a human phenomenon. Understanding these new insights should help us all to live with the stress of the separation or loss of loves ones by allaying our own anxieties and fears about our reactions during periods of grief and mourning.

All of us will suffer grief at some time. My first experience of loss occurred when my maternal grandmother died. I was unprepared for my distress and that of my family. Throughout the next two years I experienced cycles of anger and sadness. My parents and friends worried about me, but I had forgotten by that time that it had all began when my grandmother died. I isolated myself from them and continued to feel upset for those two years. Slowly the feelings passed and I found myself more inter- ested in studies, friends, family and life. It was only much later I realized the cause of those years of withdrawal.

Explanations of the feelings which we suffer when separation and loss occur begin with a central truth. Our feelings after a loss are the price we must pay for our attachment to other people. Attachment (loving others), separation and loss are all part of the same process of committing ourselves to others. Our attachments are related to similar behaviour in our close relatives in the animal world and can be thought of as being based in instinctive attachment behaviour and bonding. The development of attachments seems to function as an evolutionary necessity. Separation from loved ones results in similar patterns of anxiety, fear, anger and sorrow in children, adults and animals. Separation anxiety seems necessary in order that the object of one's attachment will be searched out and recovered if at all possible. The development of fear of separation and anxious attachments in children and adults is commonplace. Both anger and sorrow play a role in the events following separation so that these emotions are natural consequences to it.

Loss, as discussed here, is a permanent parting with a valued person, place or object. The inevitability of loss makes it a universal occurrence. Bereavement is the loss of a loved one. Grief is the feeling accompanying such a loss, while mourning is the act of grieving through which the bereft person passes. Loss is a very special type of separation in that no amount of self-generated feeling or behaviour will allow the recovery of the lost object. There are three parts of this process: attachment, separation and loss. They are a natural progression and serve to give a perspective on the normal mourning process.

\section{Normal grief reactions}

My reactions to my grandmother's death would have been less disturbing to me if I had known what to expect. Normal grief reactions occur in stages with recognized feelings, behaviours and thoughts occur- 
ring in each stage: Stage I: numbness and 'shock'; Stage II: pining, searching, anger, sorrow-depression and disorganizations; Stage III: resolution. Throughout Stage II normal symptoms include: somatic distress such as palpitation, sleeplessness, preoccupation with the image of the deceased, guilt, hostility, loss of patterns of conduct, and pining and searching behaviour, anger and depression.

\section{Bereavement counselling}

In the hope of preventing the development of morbid grief reactions from occurring, bereavement counselling has been instituted as a preventative measure both in England and the United States. Bereavement counselling is held to follow certain principles.

Initial comfort during the stage of numbness allows the bereaved time to take in what has occurred. The counsellor tries to accept the pain of bereavement without inhibiting the expression of grief. He or she reviews the relationship which the deceased shared with the bereaved including: (a) a discussion of guilt, (b) working through of hostility, (c) expression of sorrow and loss and (d) attention to the fear of changes in feelings towards the deceased. The counsellor helps to make real the fact of the loss without forcing at an early stage. The bereaved should be reassured that the process of grief is normal and that the feelings, dreams or hallucinations are expected and accepted. Eventually, new patterns of conduct are hoped for, usually of course involving friends and relatives known to the bereaved. This form of counselling aims at those who know of their loss and are acutely aware of the relevance of it to their lives and emotional well-being.

\section{Morbid grief reactions}

Descriptions of morbid or atypical grief reactions were classified originally by Lindemann (1948). He recognized three broad categories: absent reactions, delayed reactions and distorted reactions. The last of these he recognized as including overactivity with a sense of loss, acquisition of symptoms belonging to the last illness of the deceased, onset of a medical illness, alteration in relationship to friends and relatives, furious hostility against specific persons, woodenness and absence of emotional display, lasting loss of initiative and decision-making ability, activity detrimental to social and economic existence, and a syndrome of agitated depression including suicidal thoughts and activities. Meanwhile Parkes (1972) has stated that the absence or delay of grief longer than 2 weeks in a situation in which it would have been expected, extreme excess guilt or identification symptoms were significantly indicative of morbid grief reactions. He further reports that panic reactions, extreme excess anger, and persisting intense grief were associated danger signs that mourning was not proceeding well.

Bowlby (1981) believes that one of the main characteristics of pathological mourning is an inability to express overtly the rage to recover and scold the lost object with all the yearning for and anger with the deserting object that they entail. These urges are felt to continue as active systems in the personality and come to influence feeling and behaviour in strange and distorted ways. It is in this latter category, that of morbid grief, that chronic persistent reactions to loss occur. Although recent work has been done in an attempt to relieve the effects of morbid grief on the individual suffering from it, these attempts are by no means universally successful (Mawson et al., 1981).

Morbid grief in the individual distorts or delays the normal grief process. In a clinical study of 19 patients suffering from morbid grief, Lieberman (1978) evaluated their signs and symptoms using a Morbid Grief Scale based on the work of Lindemann, Parkes and others. The scale includes many of the most frequently observed reactions, including absence of expected reaction, delayed reaction, avoidance, panic attacks, anniversary reactions, over-idealization, identification symptoms, recurrent nightmares, extreme anger, extreme guilt, prolonged grief and physical illness.

Correlations of these items revealed three patterns. First, a pattern of avoidance in which avoidance of persons, places or things related to the deceased combines with extreme guilt and anger and a delay of onset greater than 2 weeks. The second pattern showed an absence of expected grief to be coupled with idealizing the deceased and extreme anger directed towards others. The third pattern was the combination of prolonged grieving with recurrent nightmares and the development of a physical illness.

\section{Some illustrative case histories}

These individual reactions seem to parallel a more general family reaction to loss. For example, the first pattern was translated into family relationships in a family of four in which the death of a child was never mentioned nor were his pictures viewed nor was his name mentioned. Avoidance of his death and its impact became a family rule. The second pattern is illustrated in the family where after the death of their father, an irascible and difficult man, little emotion was shown by his wife, but the funeral was marred by an angry tirade from her towards her oldest son. This resulted in the ostracism of the son from the rest of the family as the scapegoat who 'killed' father because of his behaviour. The third pattern occurred in the family of a woman whose husband died. She 
developed asthma and late onset diabetes during the following year while her prolonged bouts of crying and nightmares in which her husband rose from the grave caused her children to cease to visit her until she was completely isolated as were the children one from the other.

Other reaction patterns seem more uniquely manifested in the family dynamics and interactions, rather than being isolated in the individual. Family losses are often followed rapidly by family gains through marriages or births, as if in an attempt at restitution. For example, when my paternal grandfather died, the following year saw the birth of 5 great grandchildren and two marriages amongst the 11 grandchildren. The significance of the act of marriage or conception and birth lies in the replacement of those who have died. Replacements in a family can be conscious or unconscious, covert or obvious. The effect on the spouse or child who becomes the replacement may be negligible or catastrophic depending on the reality of their attributes, the strength of the projections and the way in which the two match. Equally important is the conscious awareness of both the receptacle of the projections as well as the projector.

As an example of the way in which the unconscious projection of a dearly loved but dead relative can affect the child who received those projections, I would like to use the S. family. Miss S. a 17-year-old anorectic girl was born 10 months after her paternal grandmother died. Her father had been very close to his mother as evidenced by their enforced separation only during the war. After the war he returned to the family home and remained there even after marriage. His wife became pregnant purposely in order to force him to move, a manoeuvre he never forgave her for. Shortly after the move and birth of his son, his mother became ill and died 2 years later. His daughter was born the year following her death. When she was born he felt she looked exactly like his mother. She grew up with him treating her as if she were his mother and he developed the same overclose relationship with her. When she became an adolescent he stifled her independence while his wife was continuously angry and jealous of her daughter's closeness with her husband. She was unaware of the reasons for the growing tension at home, but when her body began to develop and it was clear that she would take after her mother's more voluptuous form, her father began to comment unfavourably. Her paternal grandmother had been very thin all her life and she began to slim with her father's encouragement. The anorexic illness took over and she had to be admitted to hospital. This example illustrates the unconscious use of a child as a container to be filled with the relationship patterns pre-established with a dead relative. Children who serve as replacements can face enormous difficulties related to their even- tual growth into adulthood. Separation from parents is a particularly difficult task when the parent is projecting an unseparated dead relative onto the child.

Another example of replacement is that of the birth of one child who then replaces another child who has died. The child must live with the projections of both parents. Kevin was a 16-year-old boy whose parents had married as a result of the first pregnancy. The child born of this pregnancy lived for only 3 months and was remembered by the parents as perfect in every way. This perfection was projected onto Kevin whose normal behaviour was perceived as extremely disruptive. He did not fit the projection while his parents could not let go of their image of the child which had forcibly cemented their relationship. Kevin's mother was treated for depression for over 20 years while her husband attended spiritualist sessions in an attempt to get in touch with their dead baby.

Finally, I wish to mention another common enough family pattern related to loss. This is the destruction of families which can occur after a loss either through further deaths, divorces, illnesses or separations. Mr and Mrs D. were happily married for 3 years until Mr D's father developed lung cancer. $\mathrm{Mr} \mathrm{D}$. began to show jealousy and became suspicious of his wife. He started drinking heavily. When his father died he began to beat her. He starting going out with other women. He rarely saw his mother or brother who lived nearby. His wife finally divorced him. His only sibling, an older brother, also had several affairs and his marriage ended. Neither brother could discuss their father's death with their mother. Mr D. denied that his father's death had any effect on his behaviour although he also admitted that when his father became ill he began to wonder for the first time in his life what life was all about.

\section{Living with loss}

Living with the results of loss can be very emotionally trying on the bereaved as well as those others around them. The impact of the effects of loss can be chronic; it is, after all, a permanent condition in the sense that no replacement can ever completely make up for the original loss.

I wish to illustrate this phenomenon of living with loss with representative statements presented from the point of view of the bereaved rather than that of the professional helper.

A. 'My mother died 4 years ago. She was a remarkable woman. We knew that she might pass away so it was not too much of a shock. Actually I never had time to feel her loss because our daughter was born around the same time. We gave her my mother's name as her middle name because she 
looked so like my mother. My father thinks she acts like my mother as well. They are both stubborn and very emotional. My daughter is a very great comfort to me. I spend a great deal of time with her. My mother and I were always very close. I used to 'phone her every week up to the week that she died. Everyone remarked on how calmly I took her death but I suppose it was an expected death and I never really felt that I lost her somehow. My wife was very surprised. She thought I would go to pieces, but she was much more emotional about it than I was. The fact is that my father was so upset he had to go and live with my younger brother. We could not have him because of our daughter. I have a very special and close relationship with my daughter. I sometimes lay awake at night and think how lucky I am to have her. I couldn't bear it if anything were to happen to her. She's my life'.

Mr A. never talked about his mother after her death nor could his relatives mention her without him either going out of the room or talking about his daughter instead. He refused to go to his mother's funeral and has never visited her grave. His wife asked her family practitioner for help in dealing with him because she felt he was over-protecting their daughter.

B. 'I am 62 years old now and I have been living with loss for 15 years. My son died in an electrical accident. He wasn't to blame. He was using a drill which was wired improperly at work. I couldn't believe he was dead, even at the funeral. I still wake up at night dreaming about him. He was our perfect child. We never had any trouble with him right from birth. I'm angry with God for taking him from me. I won't go into church any more because I'm so angry. Often I can hear my son talking to me late at night. I feel he is close to me. His wife has remarried and I think she's wrong. I can't see how anyone could replace my son. I feel very angry and upset and irritable for no reason. I've had to retire early because I just found it too much to work. My other 4 children have given up on me and don't really want to see me any more because, I suppose, they have forgotten the memory of their brother. My wife and I live very separate lives now. She's always with the grandchildren, but I can't see the point.

Once, several years ago, a doctor suggested that I should go and talk to someone about how I feel, but I knew it wouldn't do any good. No one can replace my son for me. I really just want to wait out my life and join him. The doctor said I've never said "goodbye" to him and he's right. And I never will. My wife once said that our boy wasn't perfect and I hit her I was so angry. I haven't been able to visit his grave for many years and I don't look at his picture.

I spend my life waiting for it all to end and I don't really see any other way to exist. No one could ever replace my son and he was taken for me before his time. I've tried to take an interest in life, but everything I do seems to be dull and boring. I had a gardening job but I chucked it in. Sometimes I burst into tears for no apparent reason. My wife just leaves the room when I get upset. She's very hard and uncaring. She even went to my daughter-in-law's wedding.

I live with loss hoping only to be reunited with my son when I die.'

\section{Conclusions}

Advice on how to cope with the loss of a loved one can be given freely, but it is often very difficult to follow advice which asks that people face pain and suffering rather than avoid it.

The following general guidelines can be given to any person who is bereft:

Don't avoid your feelings of anger.

Don't avoid your feeling of sadness.

Don't use drugs or alcohol in order to 'blot out' your feelings.

Don't isolate yourself from other people.

Don't prevent other members of your family from talking about your relative.

Don't be afraid to discuss your feelings about your relative with friends, relatives or helpers.

Don't copy your dead relative's thoughts, ideas or behaviour unless you really consciously want to do so.

Don't hesitate to ask for help if you have recurrent nightmares about your dead relative.

Don't place your dead relative on a pedestal or idealize them.

Do notice if your feelings worsen on anniversary dates which were important to you and your dead relative.

Don't rush your grief in order to get it over with quickly.

Don't prolong your grief in order to keep the memory of your relative painfully fresh.

Don't hide away your photos or other memorabilia to avoid grief.

For those who have to cope with relative or friends who are bereft the following guidelines may be of use:

Don't overprotect your relative.

Don't insist on your relative being 'treated' as if they were ill.

Don't be offended at your relative's angry feelings.

Don't compulsively try to 'cheer up' your relative.

Don't help your relative avoid thinking about the object of their loss.

Don't avoid talking about the loss in order to protect your relative. 
Do encourage your relative to express his/her feelings.

\section{References}

Bowlby, J. (1981) Loss. Penguin Books, London.
LIEBERMAN, S. (1978) Nineteen cases of morbid grief. British Journal of Psychiatry, 132, 159.

LINDEMANN, E. (1948) The symptomatology and management of acute grief. American Journal of Psychiatry, 53, 322.

MAWSON, D., MARKS, I.M., RAMM, L. \& STERN, R.S. (1981) Guided mourning for morbid grief. British Journal of Psychiatry, 138, 185. Parkes, C.M. (1972) Bereavement-Studies of Grief in Adult Life. Tavistock Publications, London. 